\title{
Análise e Design de Ecossistemas de Negócios usando a Abordagem Blueprint de Valor: Um Estudo Empírico
}

\author{
Luciana A. Almeida ${ }^{1}$, Cleidson De Souza ${ }^{1,2}$ \\ ${ }^{1}$ Programa de Pós-Graduação em Ciência da Computação - UFPA - Belém, PA - Brasil \\ ${ }^{2}$ Instituto Tecnológico Vale - Belém, PA - Brasil \\ lu.abdon.si@gmail.com \\ cleidson.desouzalacm.org
}

\begin{abstract}
A startup is a company created in the context of extreme uncertainty and risk. Despite this, a rich set of startups can bring economic benefits to the geographic region where they are located. Thus, there is strong interest aimed at assisting in the creation and success of these startups. However, an important aspect of these startups, the business ecosystem in which they operate and the risks management associated with this ecosystem, is often overlooked. One exception is the value blueprint approach. Thus, this work describes an empirical study aimed at the application and analysis of the value blueprint in a qualitative study with startups.
\end{abstract}

Resumo. Uma startup é uma empresa em fase inicial criada em condições de extrema incerteza e riscos. Um rico conjunto de startups pode trazer benefícios econômicos para a região geográfica onde elas estão localizadas. Assim, existem diversos estudos visando auxiliar na criação e no sucesso destas startups. Entretanto, estas pesquisas não enfatizam um aspecto importante destas startups: o ecossistema de negócios onde elas estão inseridas e a gestão dos riscos associados a este ecossistema. Uma exceção são as pesquisas que utilizam a abordagem conceitual blueprint de valor. Assim, este trabalho descreve um estudo empírico com o objetivo de analisar como a blueprint de valor pode auxiliar um conjunto de startups.

\section{Introdução}

O crescimento acelerado de acesso a Internet entre 1995 e 2000 , durante a primeira bolha da Internet, apoiado pela convergência digital e o aumento da largura de banda (Leon 2009), possibilitaram o desenvolvimento de modelos de negócios para oferecer produtos/serviços diferenciados através de um meio digital. Nesse período surge, no mercado de tecnologia, o termo startup, definido como "uma organização formada para encontrar um modelo de negócio repetível, escalável e rentável" (Ries, 2012). Ou seja, empresas recém-criadas que visam transformar ideias em produtos. Estas empresas estão inseridas em um contexto de riscos e incertezas e contam com poucos recursos financeiros. Isto quer dizer que as principais técnicas e ferramentas de planejamento elaboradas durante o século XX já não acompanham as necessidades de negócio atuais.

De acordo com uma pesquisa de Shikhar Ghosh (Gage 2012) existem evidências de que três quartos das empresas apoiadas por capital de risco não retornam o capital dos investidores nos EUA. O National Venture Capital estima que $25 \%$ a $30 \%$ dessas empresas falham e mais de $95 \%$ não vêem o retorno planejado sobre o investimento 
(Gage 2012). Assim, profissionais de várias áreas - administração, TI, etc - buscam desenvolver ferramentas, metodologias e abordagens que se adequem ao desenvolvimento e gestão de produtos. Alguns exemplos são: design thinking (Mueller e Thoring 2012); customer development (Blank 2012); Business Model Canvas (BMC) (Osterwalder e Pigneur 2010) e lean startup (Ries 2012).

Para complicar ainda mais este quadro, as startups emergem em um cenário de negócios diferenciado: as cadeias tradicionais de valor já não representam a realidade das relações entre as partes do negócio. O termo que melhor representa este cenário é denominado de ecossistemas de negócios. Moore (1993) define ecossistemas de negócios como "uma estrutura dinâmica de organizações interligadas que dependem umas das outras para a sobrevivência mútua." Isto quer dizer que muitas organizações de software já não funcionam como unidades independentes que podem oferecer produtos isolados. Ao contrário, existe uma grande dependência entre produtos e empresas, isto é, as empresas precisam colaborar para que todas tenham sucesso (Taveira 2012).

Adner (2012) argumenta que "com frequência cada vez maior, o sucesso depende não só de sua capacidade de cumprir promessas, mas também do quanto uma série de parceiros - alguns visíveis, outros não - conseguem cumprir o que prometem". Isto significa que, grande parte dos gestores focam em gerenciar os riscos de execução de seus projetos. No entanto, estes gestores não gerenciam as dependências que existem em um projeto, isto é, as dependências entre as diferentes empresas de um ecossistema de negócios (Adner 2012). Visando endereçar este problema, Adner (2012) propõe a abordagem blueprint de valor para auxiliar a identificação desses riscos. Esta também auxilia na visualização do ecossistema e de todos os elementos envolvidos no mesmo. Em outras palavras, o blueprint de valor é uma abordagem que torna explícito o ecossistema e suas dependências.

Assim, este trabalho descreve um estudo empírico com o objetivo de avaliar a blueprint de valor. Este estudo foi conduzido com um conjunto de startups de tecnologia da informação incubadas em uma agência de tecnologia e inovação. Utilizando uma abordagem de pesquisa qualitativa alguns integrantes de startups foram entrevistados e os relatos da utilização da blueprint de valor foram analisados. Os resultados descrevem as vantagens, desvantagens e sugestões de melhoria da blueprint de valor.

O restante deste artigo está organizado da seguinte forma. A Seção 2, a seguir, descreve os principais conceitos necessários para o entendimento deste trabalho incluindo, ecossistemas de negócios e riscos de negócios. A Seção 3, apresenta a análise e o design de ecossistemas utilizando a blueprint de valor. A Seção 4, mostra a metodologia utilizada nesta pesquisa. Depois disso, a próxima Seção explica os resultados do trabalho. Então, a Seção 6, apresenta uma discussão sobre esses resultados. Finalmente, a Seção 7, traz as considerações e trabalhos futuros.

\section{Ecossistemas e Riscos de Negócios}

\subsection{Ecossistemas de Negócios}

O termo Ecossistemas de Negócios é inspirado no conceito de ecossistemas biológicos. O conceito de ecossistema foi formulado para especificar o comportamento cooperativo 
dos organismos da natureza (Tansley 1935). A diferença entre um sistema e um ecossistema, é que um ecossistema se desenvolve gradualmente até atingir um equilíbrio dinâmico. Um ecossistema evoluído é, portanto, relativamente autônomo (Ikenami e Salermo 2015). Entretanto, esta estabilidade pode ser abalada por desequilíbrios internos ou turbulências externas causadas inclusive por outros ecossistemas. Alguns desses ecossistemas podem sequer conseguir se organizarem de forma estável e morrerem ainda incipientes (Tansley 1935).

Nesse contexto, todos os membros de um ecossistema de negócios - clientes, organizações, sociedade, ambiente e agentes reguladores - convivem de maneira coordenada ao longo do tempo. Valor é criado por meio de processos complexos e dinâmicos, que envolvem diversas relações entre os atores do ecossistema, nos quais todos devam capturar valor (Jesus 2014). Para ser mais específico, os atores interagem competindo e colaborando, principalmente para desenvolver suas próprias capacidades e, potencialmente, alcançar a governança do ecossistema (Jesus 2014).

Em vários setores da economia, uma importante mudança operada por organizações vem acontecendo. Gradualmente, estas tem deixado de usar as cadeias de suprimentos e passado a adotar parcerias e esquemas de colaboração para oferecer "soluções" melhor elaboradas (Adner 2012).

\subsection{Riscos da Co-inovação e da Cadeia de Adoção}

Muitos projetos concentram suas forças exclusivamente em nível de execução, por que gestores competentes sabem que alcançar o sucesso requer foco obsessivo nas capacidades internas da organização. Entretanto, muitas vezes estes gestores são surpreendidos pelos "pontos cegos", isto é, pelos riscos da co-inovação e/ou da cadeia de adoção (Adner, 2012). Os riscos da co-inovação consistem das tecnologias desenvolvidas externamente à empresa e que devem existir para que o produto da empresa tenha sucesso. Estes riscos independem da natureza da inovação. Ou seja, o risco pode ser tecnológico (ex: uma bateria melhor para carros elétricos), processual (um novo processo que garanta qualidade), organizacional (uma abordagem de vendas integrada que combine ofertas de várias divisões), entre outras opções. Já os riscos da cadeia de adoção referem-se aos intermediários que se encontram no caminho entre um produto e o cliente final do mesmo. Isto inclui a necessidade dos parceiros em adotar a proposta de valor, fazendo com que os clientes finais possam ter a oportunidade de conhecer o produto. Por exemplo, um lojista precisa vender o produto em suas lojas (físicas ou virtuais) para que um cliente tenha a opção de comprá-lo. Enfrentar riscos como o da cadeia de adoção pode ser decisivo no sucesso ou fracasso de novos, pois quando as cadeias de adoção são frágeis os resultados são incertos.

Os riscos de co-inovação e cadeia de adoção demonstram a preocupação com as dependências de um negócio, ou seja, os riscos fundamentais a serem considerados em estratégias de ecossistemas (Adner, 2012). Essas estratégias se baseiam não apenas na cooperação entre pessoas, mas também na cooperação entre empresas dos mais variados setores. Por exemplo, para uma indústria de automóveis, não basta produzir um carro mais confiável, veloz e eficiente: é preciso também oferecer sistemas de entretenimento e computação de bordo de última geração. Empresas de marketing devem oferecer companhas de publicidade e organizar comunidades de usuários; as telecomunicações precisam não só prover o serviço de voz, mas toda experiência de mídia, e assim por 
diante. Para ajudar a configurar este cenário Adner propõe uma abordagem, chamada blueprint de valor, que será discutida na próxima Seção.

\section{Análise e Design de Ecossistemas usando a Blueprint de Valor}

Para o processo da gestão de riscos tanto no ambiente interno da empresa quanto externo, é preciso primeiro identificar os relacionamentos atuais da organização, ou fora dela, que precisam mudar para que o produto tenha sucesso. Apenas depois desta identificação será possível iniciar a definição de estratégias para gerenciar os riscos entre as dependências (Adner 2012). Nesse sentido, a blueprint de valor, tem a finalidade de ajudar a identificar estes riscos e desenhar o ecossistema de negócios correspondente, o que Adner (2012) denomina de Mínimo Ecossistema Viável (MVE). O MVE é a menor configuração de elementos que podem ser reunidos em um ecossistema e ainda criar valor comercial. A blueprint de valor pode ser utilizada em empresas em contextos diversos. Esta pesquisa analisa sua utilização em startups.

O blueprint mostra os componentes de um ecossistema, não se concentrando apenas na identificação de componentes tradicionais de negócios (Adner 2012). Para identificar estes componentes 5 aspectos devem ser identificados: identifique o cliente final; identifique seu próprio produto; identifique seus fornecedores; identifique seus intermediários (Quem está entre os mentores do produto e o cliente final? Quem suprirá o produto após disponibilizado?; e por quem o produto deve passar para chegar ao cliente final? Além da identificação desses componentes, o blueprint de valor informa aos gestores a situação atual do ecossistema por meio de uma metáfora simples, com base no sinal de trânsito contínuo representado por luzes verde-amarelo-vermelho, para indicar o alinhamento de cada componente. Isto é, para os riscos de co-inovação, verde significa que as partes associadas estão prontas; amarelo significa que elas ainda não estão prontas, mas que existe um plano (que pode demorar um pouco, mas que será conseguido eventualmente); e vermelho que significa que essas partes não estão prontas e que não existe nenhum plano claro definido para elas. Para os riscos de adoção, verde significa que seus parceiros estão ansiosos para participar; amarelo significa que eles estão neutros, mas abertos a entrar no ecossistema; e vermelho significa que eles têm razões claras para manter a sua condição anterior e assim não participar do ecossistema tal como ele está desenhado.

A utilização do blueprint de valor permite comparar estratégias diferentes. Por exemplo, a seguir, o blueprint de valor é usado para explicar por que a Amazon e a Sony tiveram resultados tão diferentes no desenvolvimento do mercado de e-readers. A Figura 1 apresenta o blueprint de valor do Sony Reader no seu lançamento (Adner 2012). Os elementos representam: (i) E-Ink fornecedora da tela; (ii) Sony DRM para gerenciar o conteúdo entre outros componentes; (iii) o leitor digital da Sony; (iv) intermediários, os varejistas; e (v) clientes finais o grande público leitor. Além disso, um leitor digital precisa disponibilizar algo para ser lido, completando a proposta de valor aos clientes. Neste ponto entram os complementadores desse ecossistema. Ou seja, a Sony precisava convencer: (vi) os autores, editoras e seu próprio varejista, o Sony Connect.com a comprar a ideia. Porém as editoras eram problemáticas tanto em termos de co-inovação quanto nas frentes de adoção, pois aspectos econômicos e jurídicos desta nova tecnologia deveriam ser esclarecidos principalmente quanto aos direitos autorais (Adner 2012). A falta de conteúdo adequado significou que este leitor 
não ia avançar no mercado. E por fim (vii) a conectividade, na qual o usuário precisava conectar o leitor ao PC para transferir o livro comprado para o leitor.

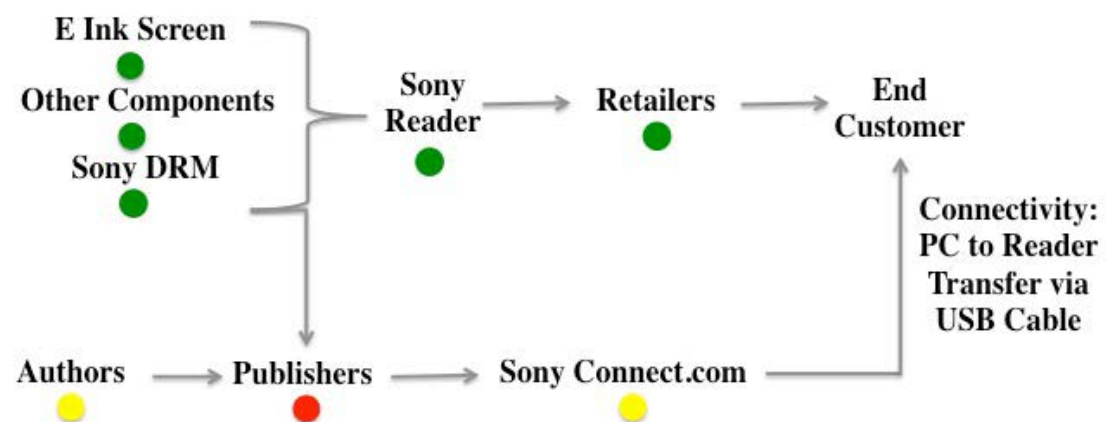

Figura 1. Exemplo de um blueprint de valor (Sony Reader). Adaptado de: Adner, R. (2012).

Este exemplo ilustra como o blueprint de valor permite a identificação de incertezas no caminho do conteúdo até o dispositivo, independente da excelência do hardware. Estas incertezas no ecossistema sugerem a um novo conceito utilizado no contexto da blueprint de valor: a reconfiguração do ecossistema. A reconfiguração de um ecossistema consiste na alteração das interações entre os elementos no sistema, ou seja, em atuar para mudar o risco dessas relações. O blueprint de valor é usado como ponto de partida tal que, a partir de qualquer elemento do mesmo, é possível alterar o arranjo de atividades, atores e links do mesmo. Isto é feito fazendo cinco perguntas fundamentais: $\mathrm{O}$ que pode ser separado? $\mathrm{O}$ que pode ser combinado? O que pode ser mudado? O que pode ser adicionado? O que pode ser retirado? (Adner 2012). A partir destas perguntas é possível pensar em uma reorganização dos elementos do ecossistema presentes na blueprint de valor, e assim, mitigar os riscos do ecossistema (fazendo com que as cores se tornem "verdes") para o lançamento de um produto. A possibilidade de reconfigurar um ecossistema ajuda a refletir sobre os pontos necessários para a criação de um ecossistema de valor para um produto.

A Figura 2 apresenta o exemplo de blueprint de valor para o lançamento do Kindle da Amazon. Os elementos representam: (i) complementadores iniciais, como a conectividade sem fio no dispositivo desenvolvido, o que permitiria a utilização da rede da Amazon para baixar o livro instantaneamente, (ii) o uso de uma arquitetura fechada e proprietária para prevenir que os livros sejam copiados, impressos, ou colocados disponíveis de forma ilegal e que por sua vez reduziriam os riscos de adoção pelos editores e autores (com luzes amarelas). Além disso, (iii) o Kindle oferecia inicialmente 90 mil títulos em sua biblioteca, além de oferecer aos seus clientes (iv) Amazon.com preços de livros com valores bem reduzidos em comparação com os títulos impressos, e com isso, a Amazon lucra sobre a venda de seus dispositivos (Adner 2012).

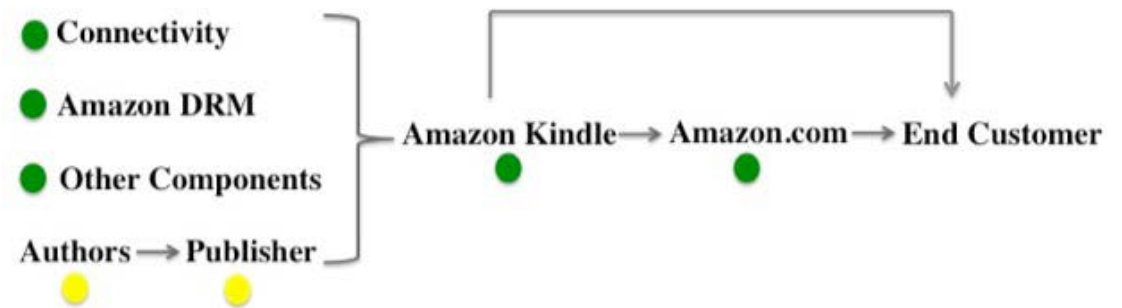

Figura 2. Exemplo de um blueprint de valor (Kindle da Amazon). Adaptado de: Adner, R. (2012). 
Em outras palavras, a Amazon apostou em um ecossistema melhor estruturado oferecendo aos usuários uma proposta de valor mais completa. Os gestores desenharam uma estratégia extremamente segura para as editoras (quanto ao conteúdo) e forneceram uma experiência completa e confortável para os usuários finais.

\section{Metodologia}

\subsection{Visão Geral}

Este trabalho descreve uma pesquisa empírica. Estudos desta natureza auxiliam a entender como e por que as coisas funcionam e nos permitem usar esta compreensão para alterar nosso mundo materialmente em várias áreas (Silva e Menezes 2001). Nesse contexto, existe um conjunto de estratégias para coletar informações a respeito da realidade estudada, que compreendem a metodologia. Em vista das metodologias disponíveis, a selecionada para a condução deste trabalho é a metodologia qualitativa (Silva e Menezes 2001) que permite compreender e avaliar a utilização de uma ferramenta ou abordagem por um grupo de profissionais.

Nesse sentido, a pergunta de pesquisa elaborada para nortear este estudo é a seguinte: "Como a abordagem blueprint de valor pode contribuir com as startups de software no contexto da gestão de riscos de ecossistemas de negócios? ". Para ajudar a responder a essa questão optou-se pela coleta de dados com base em entrevistas semiestruturadas individuais e coletivas (Silva e Menezes 2001). Estas possibilitam maior liberdade no momento da entrevista, e com isso pode-se explorar outras perguntas/respostas, dando liberdade também aos entrevistados. As entrevistas foram realizadas no mês de setembro de 2015 .

Após a realização da coleta de dados, as transcrições das entrevistas e a análise de dados foram feitas. A análise de dados foi realizada com base na técnica de codificação e categorização (aberta e axial) proveniente da Teoria Fundamentada em Dados (TFD) (Strauss e Corbin 2008).

\subsection{Contexto}

O contexto do estudo compreende startups de tecnologia e de software. Esse contexto foi definido devido ao interesse em avaliar a abordagem em um cenário real. Para iniciar o processo de coleta de dados com as startups foi realizada uma pesquisa em busca de incubadoras, aceleradoras, fábricas de software, dentre outros que permitiriam a realização da pesquisa. Após um contato inicial, obteve-se uma resposta positiva da incubadora $\mathrm{A}^{1}$. Assim, depois de diversas reuniões com a direção da incubadora, a primeira atividade realizada na incubadora foi a apresentação de uma palestra sobre a abordagem blueprint de valor. Esta foi ministrada em agosto de 2015 e teve a participação de onze startups incubadas. As startups tiveram liberdade para decidir participar, ou não, deste estudo. Assim, das startups presentes na palestra três tiveram interesse em participar. Estas startups serão mencionadas neste trabalho apenas como startup - 1, startup - 2 e startup - 3 por motivo de confidencialidade.

\footnotetext{
${ }^{1}$ Por motivos de confidencialidade, o nome das startups e dos participantes de todo o processo desta pesquisa serão anônimos.
} 
A segunda atividade realizada foi um mini-workshop com as startups. Este workshop foi dividido em dois momentos. Primeiro, a apresentação dos conceitos sobre a blueprint de valor de forma detalhada. Nesse momento, explicou-se o passo-a-passo para a construção de um blueprint de valor, por meio de vários exemplos. E, segundo, foi sugerido aos empresários que elaborassem o blueprint inicial de seus produtos. $\mathrm{O}$ primeiro contato dos empresários com a blueprint foi mediado pela primeira autora, $\mathrm{o}$ qual se propôs a auxiliar na elaboração do blueprint de valor e a tirar dúvidas sobre a abordagem de um modo geral.

Ao final do mini-workshop foram entregues aos empresários um documento contendo alguns exemplos de blueprints e as atividades a serem realizadas por eles como: a versão inicial do blueprint e as descrições dos possíveis riscos (co-inovação e cadeia de adoção) encontrados. Os empresários tiveram duas semanas para realizarem estas atividades.

Novas reuniões de acompanhamento foram marcadas durante o mês de setembro, para que dúvidas adicionais pudessem ser respondidas e para que houvessem discussões acerca dos blueprints elaborados pelas startups.

Finalmente, entrevistas com os empresários das startups foram realizadas para buscar respostas para a questão de pesquisa, que retrata a contribuição da blueprint de valor no cenário de ecossistemas de negócios de software. A seguir são apresentados os processos de coleta e análises dos dados.

\subsection{Processo de Coleta e Análise dos Dados}

$\mathrm{Na}$ etapa de coleta de dados foram realizadas 3 entrevistas, sendo 2 informantes na "startup - 1", 1 informante da "startup - 2" e 1 informante da "startup - 3". Estas entrevistas foram gravadas para posterior análise. Além disso, informações foram coletadas nos vários momentos de interação entre pesquisador e participantes da pesquisa antes das entrevistas, o que colaborou para o desenvolvimento da entrevista semi-estruturada. Em média foram realizados 4 encontros com cada empresário ao longo de 2 meses de coleta de dados, sendo que cada reunião em média durou 3 horas e as entrevistas tiveram em média duração de $90 \mathrm{~min}$. Estas reuniões foram realizadas para discutir os blueprints elaborados, bem como, para entender como esta abordagem estava sendo entendida e utilizada pelos empresários.

As entrevistas foram realizadas com o apoio de um guia de entrevistas. Este guia é composto por perguntas sobre as vantagens, desvantagens e sugestões de melhorias para a blueprint. Porém, para ajudar a alcançar o objetivo da pesquisa de forma ampla outros questionamentos foram incluídos no guia como: "utilizam outras ferramentas ou abordagens de projeto?", "qual o estágio do produto?", "a abordagem ajuda na comunicação?" Se sim "em que situação? Como?", e por fim, "Quando elaborar o blueprint de valor?".

As entrevistas foram transcritas e analisadas com o auxílio da ferramenta MAXQDA 11 (Verbi 2015), sendo analisada pelo método de categorização/codificação da Teoria Fundamentada em Dados (Strauss e Corbin 2008). A Figura 3 mostra as categorias resultantes codificação. 


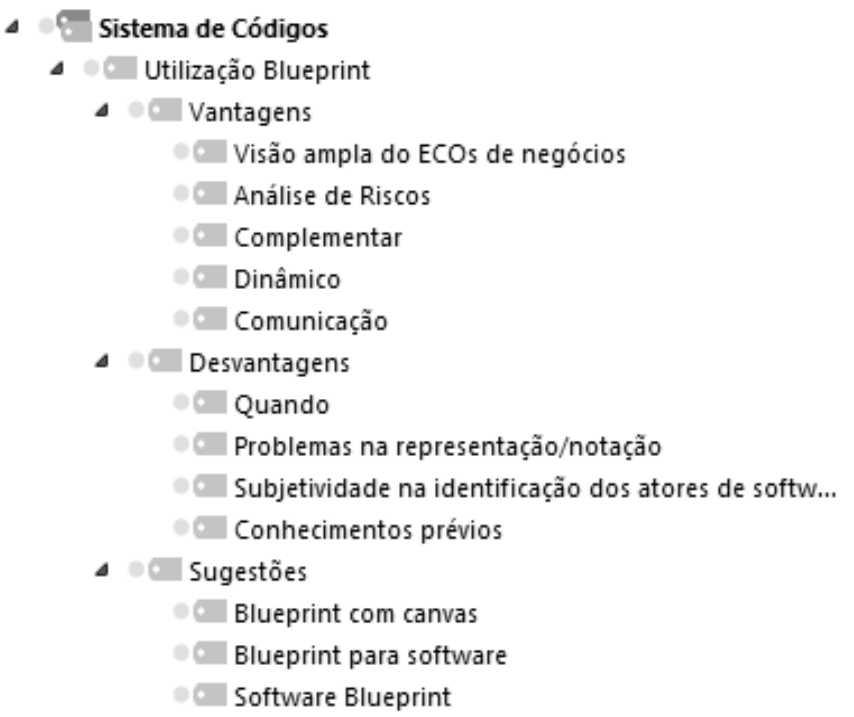

Figura 3. Lista de códigos e categorias.

$\mathrm{Na}$ Figura 3 todas as categorias e subcategorias contemplam trechos de entrevistas os quais ajudam a responder à questão de pesquisa deste trabalho. Neste instante são encontradas as categorias interessantes para a obtenção dos resultados desta pesquisa. As categorias mais relevantes são relacionadas entre si. Essas categorias são: (i) "vantagens" que são relatos com detalhes para avaliar as contribuições da abordagem no contexto estudado, (ii) "desvantagens" com relatos sobre pontos que podem ser considerados problemáticos, e, finalmente, (iii) "sugestões" apresentadas pelas startups para a abordagem. Cada uma destas categorias é discutida em detalhes na próxima Seção.

\section{Resultados}

Esta pesquisa buscou analisar a utilização da abordagem blueprint de valor no cenário de ecossistemas de negócios de software. Isto foi possível ao analisar as opiniões sobre as vantagens, desvantagens e sugestões para a utilização desta abordagem. Todos estes aspectos emergiram no estudo conduzido conforme a metodologia descrita na seção anterior.

Os resultados da análise permitem perceber, por exemplo, que a abordagem traz diversas vantagens aos empreendedores. Por exemplo, ela oferece uma visão ampla acerca dos elementos que compõem seus ecossistemas. Além disso, a análise de riscos sobre esses elementos pode ser utilizada de forma complementar a outras abordagens. Finalmente, ela é uma abordagem dinâmica e facilita a comunicação entre os profissionais da startup. Entretanto, a abordagem também apresenta desvantagens, entre elas o fato de ser subjetiva e o fato de não ser claro o melhor momento para sua adoção. Em decorrência de alguns pontos específicos entre as vantagens e as desvantagens os entrevistados deram algumas sugestões baseadas em seus produtos e negócios. Cada um destes resultados - vantagens, desvantages e sugestões - serão apresentados a seguir. Ressaltando que as sugestões serão mencionadas juntamente as seções de vantagens e desvantagens pois surgem em decorrência de pontos específicos destas. Seguindo a tradição qualitativa, cada um destes resultados é apresentado acompanhado de trechos dos dados coletados nas entrevistas. 


\subsection{Vantagens}

Dentre as vantagens mencionadas pelos entrevistados as principais são: o blueprint permite uma visão ampla do ecossistema de negócios e análise de riscos de co-inovação e da cadeia de adoção, facilita a comunicação, dinamismo e finalmente, ele é complementar a outras modelos e abordagens.

Quanto a visão ampla dos ecossistemas de negócios, os entrevistados apontam as vantagens em se ter conhecimento acerca dos componentes técnicos, de projeto e de negócios de seus ecossistemas, e principalmente em se identificar esses componentes. Isso compreende desde fornecedores, distribuidores, parceiros-chave até os clientes finais e ainda todos os complementadores de um ecossistema. Os trechos de entrevistas a seguir ilustram esta vantagem:

“(...) o principal é conseguir ver de uma forma geral o teu ecossistema né? Consegui ver no meu caso desde os fornecedores até o cliente final...” Startup 2.

A startup 2 afirma que o blueprint conseguiu ajudar a definir os papeis existentes em seus negócios permitindo a descoberta das dependências e do melhor caminho a percorrer para expandir o negócio.

"Mas no que [o blueprint] me ajudou foi [em] saber a relação entre o fornecedor e a gente. Não especificamente no fornecimento, quem vai ser [o] fornecedor [ou] quem não vai, mas na relação que a gente tem com fornecedor, que poder a gente tem, que poder a gente não tem. Acho que me ajudou a perceber isso. " Startup - 2 .

A vantagem da análise de riscos agrupa relatos sobre duas diferentes vantagens: a primeira abrange as vantagens em conhecer os possíveis riscos adicionais existentes nos ecossistemas; e, a segunda expõe o quanto é importante tentar de alguma forma mitigar esses riscos e contornar a situação. De fato, os resultados sugerem a importância da reconfiguração do ecossistema (ver seção 3), isto é, nas estratégias para mitigar todos os gargalos problemáticos para o lançamento de um produto.

Os empresários tiveram a oportunidade de elaborar seus blueprints de valor e a partir deste realizar a análise dos riscos (ver seção 4). Dessa forma, eles descreveram a seguinte vantagem:

“(...) outra vantagem é que eu consigo analisar muito bem a partir desse ecossistema montado, os riscos de cada ponto em cada item do meu sistema, em cada nó, eu vou chamar de nó ... do ecossistema eu consigo ver quais são os meus principais riscos, as principais vantagens, os prós e os contras (...)" Startup - 2 .

A startup - 2 descreve que após a elaboração do blueprint "a gente consegue a partir daí elaborar uma estratégia de ação, a partir daí a gente já usa outras coisas alguma pesquisa que a gente fez de mercado com os clientes e fica mais fácil de ver los riscos], neste gráfico do que num 'textozão' [o entrevistado refere-se ao texto do plano de negócios, que também menciona análise de riscos externos]."

Prosseguindo com a análise das vantagens da bluerprint, tem-se que: avaliar as configurações alternativas para um ecossistema, é reconfigurá-lo (ver seção 3). Devido a essa possibilidade, os entrevistados classificaram a abordagem como dinâmica. Com a 
elaboração do blueprint de valor é possível entender, acompanhar a evolução e fazer alterações no mapeamento que irão refletir na configuração real do ecossistema. Como relata a startup -2 .

(...) eu achei muito legal muito legal mesmo, porque é visual, eu gosto de ver coisas gráficas, eu acho que todo mundo né? A gente olha uma figura e já entendeu, não precisa estar em um texto explicando, a gente já entendeu aquilo ali e eu acho que o blueprint é assim, igual o canvas, ajuda bastante e é bem dinâmico eu gostei disso."

O entrevistado da startup 2 reforça também o caráter visual da abordagem que é útil, pois desta forma é possível que os poucos integrantes da startup possam terconhecimento de um ou mais setores dentro do negócio.

A abordagem por não se tratar de uma ferramenta computacional, a elaboração e alteração do mapeamento é feita de forma manual. Em vista disso, os entrevistados reportam uma sugestão que é a elaboração de um software para auxiliar no design de diagramas blueprint, tornando a criação do blueprint mais interativa.

Outra vantagem destacada é que o blueprint facilita a comunicação entre os profissionais da startup. Nesse sentido a startup 3 relata:

“(...) a abordagem é interessante, porque, tu tens que te debruçar numa realidade e ela provoca um debate, isso que é legal né? Então, tu viste? Nós começamos a conversar e as horas se passaram e ela provoca o debate e tu começas a ver realmente a realidade da empresa, começa a olhar a empresa, $o$ ambiente, o ecossistema da empresa. Acho que o grande benefício é esse, provocar o debate em cima do negócio”. Startup - 3.

A startup 2 relatou uma situação positiva com relação a comunicação dentro de sua equipe, como relata a seguir:

“...por exemplo naquela primeira análise que a gente fez eu desci lá expliquei para os funcionários e eles já conseguiram perceber um monte de coisas que não percebiam, então porque a gente não corta aqui e 'faz assim, faz assado', então ficou bem legal pra trabalhar. " Startup - 2.

Por fim, a última vantagem identificada é o fato da abordagem blueprint complementar outras abordagens e modelos já utilizadas pelas startups. Esses modelos e abordagens para gestão de projetos são: plano de negócios (Rosa 2013) e o Business Model Canvas (BMC²) (Osterwalder e Pigneur 2010). O plano de negócios é um dos requisitos obrigatórios para que estas startups pudessem candidatar-se a uma vaga na incubadora. Pode-se constatar que as startups consideram o plano de negócios necessário, porém caracterizam-no como uma abordagem textual pouco dinâmica, pois sentem a necessidade de consultá-lo sempre que necessário, mas encontram grande dificuldade para analisar certos pontos em meio a uma "prosa gigante" como o entrevistado da startup 1 se refere ao seu plano de negócios. A seguir um relato da startup 3 sobre isto:

\footnotetext{
${ }^{2}$ Osterwalder e Pigneur (2010) apresentam o Business Model Canvas (BMC) que é um modelo composto por 9 blocos, os quais ajudam a empreendedores criarem seus modelos de negócios, por meio de conceitos sobre como uma organização cria, entrega e captura valor.
} 
"O plano de negócios ele é uma coisa meio trabalhosa e acaba se tornando pouco dinâmica, né? É o 'documentozão' e a gente tem que analisar muitas coisas. O canvas não, é um negócio que a gente tá vendo visualmente, que a gente pode alterar rapidamente e o blueprint a mesma coisa. " Startup - 3.

$\mathrm{O}$ modelo mencionado pelos entrevistados é o BMC. Esta modelo é muito utilizada e bastante elogiada principalmente pela agilidade de visualização que proporciona aos entrevistados sobre seus modelos de negócios. As startups mencionam que ao fazerem seus blueprints perceberam que os riscos externos não faziam parte do canvas, que eles já haviam elaborado, e por isso relatam que a elaboração do blueprint de valor dos seus ecossistemas após a elaboração de seus canvas os ajudou a perceberem os pontos cegos de seus negócios com maior eficiência. A startup 1 relata:

“...a gente adiciona alguém ou tira alguém? Vai atualizando [o] blueprint como a gente atualiza o canvas, entendeu? Porque como eu te falei, tem muita coisa que tá no blueprint que não está no canvas por isso que eu acho que [o blueprint] complementa o canvas. ” Startup - 1 .

Em meio às entrevistas, a startup - 2 faz uma sugestão, que é uma fusão entre a abordagem blueprint de valor e o BMC, como pode ser visto nos trechos de entrevistas a seguir:

“(...) o que eu acho que seria muito interessante mesmo era fazer uma espécie de fusão do canvas com o blueprint aí eu acho que ficaria um negócio bem legal mesmo, bem dinâmico, por que se juntar o canvas com o blueprint eu acho que sai uma coisa sensacional, porque o blueprint consegue avaliar os riscos daquele modelo lá do Canvas se aquilo é válido ou não. ”. Startup - 2.

\subsection{Desvantagens}

Esta seção analisa os relatos sobre as desvantagens da abordagem tem-se: subjetividade quanto a identificar os atores de software e quando elaborar o mapeamento.

A desvantagem quanto a subjetividade está relacionada a dificuldade de correlacionar os elementos apresentados no blueprint genérico, ao contexto de software. Um trecho de entrevista, a seguir, mostra a visão da startup 1 sobre esta questão.

"Olha uma dificuldade que eu tive com blueprint foi quando eu fui fazer foi justamente àquela questão, porque depende muito de cada produto, de cada negócio (...) seria o que pegar pra colocar [no] blueprint (...)” Startup - 1 .

A desvantagem, exposta acima, acerca da dificuldade em identificar os atores para software, gerou mais uma sugestão, os entrevistados propõem a criação de um blueprint específico para software, ou seja, um modelo pré-definido. Já que sentem dificuldade em identificar quais componentes devem considerar e como deve ser desenhada a estrutura de relacionamentos em seus ecossistemas.

Quanto a desvantagem sobre quando elaborar o blueprint ou qual o melhor momento para dar início a elaboração em negócios de software. Observa-se que as startups entrevistadas encontram-se em diferentes fases de elaboração de seus produtos, portanto, exprimem opiniões com base nesses estágios e em suas breves experiências de negócios. Nesse sentido, as startups 2 e 3 relatam que:

"Eu acho que depende, porque se fosse mais no início a gente não teria ainda amadurecido muito bem quem seriam, por exemplo, os nossos fornecedores e a 
gente não teria uma ideia realmente clara do que eu quero, nosso contexto, eu acho que no meu caso eu conheci essa abordagem no momento perfeito para minha empresa que é o momento que eu tenho muito bem definido quem são meus clientes, quem é o meu público alvo, como eu atinjo meus clientes quem são os clientes dos meus clientes, porque na verdade eu só vendo se o usuário final tiver necessidade de comprar, o meu cliente só vai me comprar se o cliente dele quiser comprar também, eu tenho muito claro toda a minha cadeia, agora [depois de usar a blueprint], desde o meu fornecedor até o desenvolvimento $e$ montagem." Startup - 2.

E por fim, a startup - 3 já tem o seu produto lançado no mercado e relata que nesta fase é interessante estruturar o blueprint, mas afirma que dependendo do tamanho da empresa, ou seja, uma empresa maior, o blueprint com certeza deveria ser elaborado antes.

“Eu não sei se no lançamento de um produto isso funcionaria (...) Dessa forma, o que acontece, para mim funcionou. Hoje digamos se não tivesse o blueprint eu teria menos uma abordagem que ajudou. E ainda tem mais, o meu produto é diferente, se eu sentar no computador agora e quiser mudar todo ele eu mudo né? Eu não mudo a alma, mas eu mudo o conteúdo, o design, a forma de passar e tudo mais. Eu tenho essa possibilidade, mas eu não sei, em uma grande empresa acho que isso deveria ser feito antes, pois requer muito dinheiro de investimento e tem que ter muito cuidado, por isso com certeza antes seria bem melhor. "Startup - 3.

A próxima seção aborda a discussão entre os resultados deste trabalho, qual o impacto positivo para o contexto de riscos em ecossistemas de negócios, e também uma comparação com estudos relacionados aos temas abordados neste trabalho.

\section{Discussão}

Os resultados da seção anterior permitem constatar que estruturar o ambiente de negócios incluindo as relações entre as empresas, bem como definir os papeis desempenhados por cada uma delas pode auxiliar a identificar e dminiuir os riscos desse ambiente, além de auxiliar a amadurecer a proposta de valor de um produto. Isto é, apenas gerenciar os riscos técnicos e de projetos, já não é suficiente para as empresas se manterem competitivas no mercado atual. Elas precisam gerenciar as relações com outras empresas de seu ecossistema. Isto é particularmente importante para a comunidade de Sistemas Colaborativos brasileira, pois a mesma tem historicamente focado em colaborações entre pessoas de uma forma direta (através de estudos empíricos) ou indireta (através de ferramentas de apoio a colaboração). Uma possível exceção para isto são os estudos de emergências e crises e estudos de processos de negócios que enfatizam colaboração entre diferentes organizações, embora geralmente focando nas pessoas e nos papeis que eles desempenham. Neste estudo, o foco é apenas na colaboração - através das dependências e dos riscos - entre organizações, sem lidar com pessoas ou papeis. Assim, este artigo visa enfatizar a colaboração em um nível de abstração diferente de estudos anteriores.

Esta seção também discute brevemente os resultados anteriores no contexto de outras metodologias existentes na literatura de startups que visam nortear e diminuir os 
riscos de negócios das mesmas. Por exemplo, o customer development ${ }^{3}$ (Blank e Dorf 2012) surgiu com a missão de tornar o processo de abertura de startups menos arriscado. Ao se comparar o customer development e a abordagem blueprint de valor nota-se que os conceitos são complementares. Ambas focam em aprendizado e não mais apenas em execução (Blank e Dorf 2012). Entretanto, a blueprint possui conceitos adicionais como a possibilidade de se projetar e visualizar o MVE do negócio (seção 3). Este MVE pode basear-se nos testes de hipóteses e experimentações do customer development e nas estratégias de reconfiguração de ecossistemas da blueprint - "as cinco alavancas para a reconfiguração de ecossistemas" (Adner 2012). Ou seja, utilizando as abordagens em conjunto, além do foco no MVP (Mínimo Produto Viável) é possível também pensar em um MVE. Isto sugere uma outra vantagem da abordagem blueprint de valor que é a permitir uma visão sobre estratégia de negócios.

Existem duas outras abordagens frequentemente utilizadas em startups, a saber: o plano de negócios e o business model canvas, ou simplesmente BMC (Osterwalder e Pigneur 2010). O blueprint se direfencia do plano de negócios principalmente por considerar a existência de um caminho a ser percorrido pelo produto até o cliente final. O plano de negócios aborda de forma geral muitos aspéctos de negócios, que podem gerar deduções de negócios precipitadas sobre as condições do mercado. Além disso, conforme apresentado na seção de resultados, ele é um documento grande que não acompanha a agilidade de empresas de software. Em contraponto o blueprint de valor é dinâmico e proporciona agilidade ao design de ecossistemas de negócios e ainda aborda a existência de componentes adicionais e a gerência de riscos.

Em relação ao BMC pode-se perceber que o mesmo aborda questões como o desenvolvimento de uma boa compreensão do ambiente da sua organização, ajudando a desenvolver modelos de negócios mais competitivos e mais fortes. Isto é, com o BMC percebe-se a preocupação em descrever a lógica de como uma organização cria, entrega e captura valor. Ele analisa também o diferencial frente a seus concorrentes, mas não aborda a visão sobre ecossistemas, e também não foi elaborado para gerenciar riscos, como a abordagem blueprint .

Finalmente, é importante comentar sobre as desvantagens indicadas da abordagem, bem como as sugestões. Devido a questões de espaço, não se pode discutir todas. A respeito da desvantagem sobre a subjetividade da abordagem. Pode-se analisar o ponto de vista a seguir. Adner (2012) apresenta uma visão sobre o ecossistema, embasada na existência de fornecedores de componentes e de fornecedores de complementos. Com base nisso, o blueprint genérico é composto por componentes comumente encontrados em ecossistemas de negócios. No entanto, dependendo do produto de software, os elementos de negócios podem distanciar-se da visão de fornecedores, distribuidores, varejistas, entre outros papeis comumente encontrados em ecossistemas de negócios. Nesse contexto, os entrevistados sugerem a criação de um blueprint específico para software, ou seja, um modelo pré-definido. Osterwalder e Pigneur (2010) chamam estes modelos de negócios com características similares de padrões. Isto é, ao se analisar o canvas pode-ser perceber que algumas empresas possuem o mesmo padrão de modelo de negócios. De maneira análoga, o blueprint para

\footnotetext{
${ }^{3}$ A metodologia customer development, descreve que a melhor maneira de achar um modelo de negócios escalável, repetível e lucrativo é executar o seguinte fluxo: definir hipóteses; criar experimentos; testar; e obter insights e voltar ao primeiro passo (Blank e Dorf, 2012).
} 
software, pode apresentar padrões diferentes para cada tipo de produto de software. Isto é algo que os autores pretendem investigar no futuro. Em resumo, acredita-se que uma análise de padrões é importante para nortear e ajudar a pensar nas estratégias e no ecossistema propriamente dito.

\section{Considerações Finais e Trabalhos Futuros}

O contexto atual de negócios tem se tornado diferente de anos anteriores a partir da integração de várias empresas, isto é, atualmente, uma empresa pode possuir diversas relações comerciais com outras. Apple e Samsung, por exemplo, ao mesmo tempo que são parceiras em um aspecto (micro-processadores) são concorrentes em outro (telefones celulares). Assim, entender as relações entre as empresas torna-se essencial para o sucesso de uma organização, especialmente startups, que estão naturalmente inseridas em um cenário de riscos e incertezas. A abordagem blueprint de valor (Adner 2012) difere de propostas por enfatizar a análise de riscos em atores de ecossistemas de negócio. Além disso, ela sugere estratégias para reorganizar o ecossistema visando aumentar as chances de sucesso de uma empresa, e especialmente startups.

Este trabalho descreveu um estudo empírico com 3 startups da área de tecnologia de informação que utilizaram o blueprint para entender o seu ecossistema, bem como, refletir em como ele precisaria ser reorganizado para diminuir os riscos destas empresas. A análise da utilização do blueprint por estas empresas mostrou que o mesmo traz diversas vantagens, embora ele ainda tenha algumas desvantagens.

De um modo geral, o trabalho foca na colaboração entre empresas, ao invés de pessoas, um aspecto pouco explorado na comunidade brasileira e internacional de Sistemas Colaborativos. Os autores esperam que este artigo sirva de motivação para outros autores realizarem pesquisa neste aspecto.

As limitações deste trabalho correspondem: ao número de participantes da pesquisa, embora tenha-se constatado contribuições e algumas desvantagens, este comportamento não pode ser generalizado; outro ponto, é que se gostaria de ter acompanhado a utilização da abordagem pelos entrevistados durante um período de tempo maior. Porém, isto não foi possível por questões de prazos e disponibilidade dos participantes.

\section{Agradecimentos}

Os autores gostariam de agradecer ao CNPq pelo financiamento desta pesquisa através dos processos 485070/2013-8 e 310468/2014-0, e em especial a Chamada 59/2013 $\mathrm{MCTI} / \mathrm{CT}-\mathrm{Info} / \mathrm{CNPq}$ com processo 440880/2013-0. A primeira autora também gostaria de agradecer a CAPES pela bolsa de mestrado.

\section{Referências}

Adner, R. (2012) "The Wide Lens - What Successful Innovators See That Others." Miss Penguin Group (USA) Inc., 375 Hudson Street, New York, USA.

Blank, S. e dorf, B. (2012) “The Startup Owner's Manual.” 571 páginas. ISBN10:0984999302.

Gage, Deborah. (2012) “The Venture Capital Secret: 3 out of 4 Start-ups Fail.” The Wall Street Journal. Small business. 2012. 
Ikenami, Rodrigo Kazuo e salermo, Mario Sergio. (2015) Ecossistema de negócio: estudo exploratório acerca da delimitação de suas fronteiras. XXXV Encontro Nacional de Engenharia de Produção. Perspectivas Globais para a Engenharia de Produção Fortaleza, CE, Brasil, 13 a 16 de outubro de 2015.

Jesus, Leandro. (2014) "Das cadeias de valor tradicionais para os Ecossistemas." Conteúdo BPM. Disponível em: < http://www.bpmglobaltrends.com.br/das-cadeiasde-valor-tradicionais-para-ecossistemas/ > . Acessado em janeiro 2016.

Leon, André. (2009) "Convergência Digital mídias Integradas. " ComCiência, Campinas, n.110, 2009.

Maurya, A. (2012) “Running Lean”. 2 nd ed., Califórnia: O’Reilly, 2012.

Mueller, Roland M.; thoring, Katja. (2012) "Design Thinking vs. Lean Startup: A Comparison of Two User-Driven Innovation Strategies.” In: International Design Management Research Conference, p. 151-160, 2012, Boston.

Moore, J.F. (1993) "Predators and Prey, A New Ecology of Competition." Harvard Business Review, May-June.

Osterwalder, A. e Pigneur, Y. (2010) “Business Model Generation." 1st ed., New Jersey: John Wiley \& Sons, Inc., 2010.

Ries, E. (2012) A Startup Enxuta. 1a ed. São Paulo: Leya, 2012.

Rosa, Claudio. 2013. Como elaborar um plano de negócios. SEBRAE 2013.

Silva, E. e Menezes, E. (2001) "Metodologia da Pesquisa e Elaboração de Dissertação. "Florianópolis- 3. ed. rev. atual. - Florianópolis: Laboratório de Ensino a Distância da UFSC. 121p. (2001). http://www.scielo.br/pdf/prod/v22n1/aop_t6_0010_0155.pdf.

Strauss, A. e Corbin, J. (2008) "Pesquisa Qualitativa: Técnicas e Procedimentos para o Desenvolvimento de Teoria Fundamentada." Artmed.

Tansley, A. G. (1935) "The Use and Abuse of Vegetational Concepts and Terms." Ecology. Ecology Society of America, v. 16, ed. 3, p.284-307, jul, 1935.

Taveira, A. (2012) "Análise dos aspectos que afetam o surgimento e desenvolvimento de um Ecossistema de Software. " 62 f. Trabalho de Conclusão de Curso (Graduação) - Ciência da Computação, Centro de Informática, UFPE, Recife.

VERBI Software. (2015) "MaxQDA - The art of text analysis. 2015." Disponível em: http://www.maxqda.com. 